\title{
Ecosystem Engineering Effects of Aster tripolium and Salicornia procumbens Salt Marsh on Macrofaunal Community Structure
}

\author{
Daphne van der Wal • Peter M. J. Herman
}

Received: 7 February 2011 /Revised: 26 August 2011 / Accepted: 19 November 2011 / Published online: 7 December 2011

(C) The Author(s) 2011. This article is published with open access at Springerlink.com

\begin{abstract}
This paper examines how perennial Aster tripolium and annual Salicornia procumbens salt marshes alter the biomass, density, taxon diversity, and community structure of benthic macrofauna, and also examines the role of elevation, sediment grain size, plant cover, and marsh age. Core samples were collected on a fixed grid on an intertidal flat in the Westerschelde estuary $\left(51.4^{\circ} \mathrm{N}, 4.1^{\circ} \mathrm{E}\right)$ over 5 years (2004-2008) of salt marsh development. In unvegetated areas, macrobenthic biomass, density, and taxon diversity were highest when elevation was highest, benthic diatoms were most abundant, and sediment median grain size was smallest. In contrast, in salt marsh areas, macrobenthic biomass and taxon diversity increased with median grain size, while the effects of elevation and diatom abundance on macrobenthic biomass, density, and diversity were not significant. In fine sediments, macrofaunal community structure in the salt marsh was particularly affected; common polychaetes such as Nereis diversicolor, Heteromastus filiformis, and Pygospio elegans had low abundance and oligochaetes had high abundance. Marsh age had a negative influence on the density of macrofauna, and A. tripolium stands had lower macrofaunal densities than the younger $S$. procumbens stands. There were no significant effects of marsh age, plant cover, and vegetation type on macrobenthic biomass, taxon diversity, and community structure. The results highlight that ecosystem engineering effects of salt marsh plants on macrofauna are conditional. Organic
\end{abstract}

Electronic supplementary material The online version of this article (doi:10.1007/s12237-011-9465-8) contains supplementary material, which is available to authorized users.

D. van der Wal $(\varangle) \cdot$ P. M. J. Herman

Netherlands Institute of Ecology (NIOO-KNAW),

Centre for Estuarine and Marine Ecology,

P.O. Box 140, 4400 AC Yerseke, The Netherlands

e-mail: d.vanderwal@nioo.knaw.nl enrichment of the sediment and mechanical hindering of macrofaunal activity by plant roots are proposed as plausible mechanisms for the influence of the salt marsh plants on macrofauna.

Keywords Benthic macrofauna $\cdot$ Mudflat $\cdot$ Salt marsh . Ecosystem engineering $\cdot$ Elevation $\cdot$ Sediment

\section{Introduction}

Salt marsh plants may act as ecosystem engineers (sensu Jones et al. 1994) in intertidal areas. The physical structure of the plants provides shade, increases habitat complexity, buffers salinity and temperature (Brusati and Grosholz 2006), and can strongly influence the hydrodynamic regime (Möller et al. 1999; Bouma et al. 2005), triggering a series of physical, chemical, and biological changes in the benthic system (Levin and Talley 2000; Neira et al. 2006; Temmerman et al. 2007; Van Wesenbeeck et al. 2007). Some studies have demonstrated facilitation of other species or communities by salt marshes (Bruno et al. 2003), while others demonstrated inhibition (Van Wesenbeeck et al. 2007) or found no effect. The balance between facilitation and inhibition of benthic invertebrates by salt marsh plants may be tipped by the aboveground and belowground structure of the plant, and may therefore vary with plant species and successional stage (Brusati and Grosholz 2006; Neira et al. 2007; Wang et al. 2010).

The effects of salt marsh plants on benthic invertebrates have mainly been studied in Spartina spp. and Salicornia spp. (see Levin and Talley 2000 for an overview), while the effects of Aster tripolium stands are unknown. Even among Spartina species, contrasting effects have been found. Lana and Guiss (1991) and Hedge and Kriwoken (2000) showed 
a higher macrofaunal biomass and species diversity in salt marshes than in nearby unvegetated mudflats for Spartina alterniflora and Spartina anglica, respectively. Brusati and Grosholz (2006) demonstrated that Spartina foliosa produced a moderate level of aboveground structure that can facilitate benthic invertebrates, whereas hybrid S. alterniflora $\times S$. foliosa had so much (aboveground) structure that it excluded invertebrates. Each invertebrate species may also be affected by the plants in a different way and (multitrophic) interactions, for example, between infaunal deposit feeders, infaunal predators, and epibenthic predators may result in a complex response of the macrofaunal community (e.g., Frid and James 1988; Bouma et al. 2009). Developed aboveground structure could also have effects on higher trophic levels such as foraging birds and fishes, both because of a change in their food resources, and because they may not be able to access the sediment (Levin et al. 2006).

A number of studies reported a smaller proportion of macrobenthic taxa feeding on benthic algae relative to detritivores, with accompanying lower macrobenthic biomass and density in S. foliosa and Salicornia virginica marshes than in adjacent unvegetated mudflats (Neira et al. 2005; Levin et al. 2006; Whitcraft and Levin 2007), as a result of a decline in algal abundance due to plant shading, stressing the importance of resource availability. Subsurface deposit feeders may also be reduced, as their burrowing activity can be inhibited by vegetation-mediated changes in the sediment and plant root structure (Van Wesenbeeck et al. 2007 for $S$. anglica, Paramor and Hughes 2004 for Salicornia europaea).

Salt marsh plants generally survive in areas where hydrodynamic conditions are already benign (low wave and current stress, low inundation stress, low sediment disturbance) and, hence, sediment is fine (e.g., Van der Wal et al. 2008a). In addition, the salt marsh plants facilitate accumulation of fine and organic-rich sediment. This positive feedback loop can result in a distinct difference in inundation frequency and sediment properties between salt marshes and adjacent mudflats (Van de Koppel et al. 2005). Talley and Levin (1999) reported on a succession from $S$. foliosa to Salicornia sp., in which the accumulation of fine sediments and organic matter could have contributed to the differences in macrofauna between the $S$. foliosa habitat (i.e., a higher abundance of invertebrates with aquatic affinities, such as polychaetes) and the Salicornia sp. habitat (i.e., a higher abundance of invertebrates with terrestrial affinities, such as insects and terrestrial isopods). Elevation and sediment properties should, therefore, be taken into account when comparing macrofauna in salt marshes colonized by different plant species and unvegetated mudflats.

It is largely unknown whether the balance between facilitation and inhibition of macrofauna by salt marsh plants could itself depend on such abiotic conditions. Cottet et al. (2007) found little effect of $S$. anglica on benthic invertebrates at high elevation, where desiccation was the dominant factor determining infaunal community structure, suggesting that the magnitude of the effect of salt marsh plants on macrofauna could depend on elevation.

This paper explores to what extent the presence of salt marsh vegetation alters biomass, density, and diversity of benthic macrofauna and macrofaunal community structure. Specifically, we tested: (1) whether macrofauna changes with sediment characteristics and elevation in a similar way in vegetated and unvegetated areas, (2) whether macrofauna changes with age of the salt marsh and with vegetation cover, and (3) whether macrofauna in Aster tripolium differs from that in Salicornia procumbens salt marsh.

We hypothesize that with the development of the salt marsh, aboveground and belowground plant biomass increase, more fine sediment is trapped (due to the aboveground plant structure attenuating hydrodynamic energy) and organic matter accumulates, and microphytobenthic cover decreases (due to shading provided by the plant canopy), all of which may affect macrofauna. We also hypothesize that the perennial $A$. tripolium has a more developed plant structure than the annual $S$. procumbens, accounting for stronger effects on macrofauna.

\section{Materials and Methods}

\section{Study Site}

The study was conducted in the Westerschelde, a coastal plain estuary in the southwest of the Netherlands (Fig. 1). The wellmixed macrotidal estuary experiences a semi-diurnal tide, and is nutrient rich and heterotrophic. The study focused on the Plaat van Walsoorden $\left(51.4^{\circ} \mathrm{N}, 4.1^{\circ} \mathrm{E}\right)$. This tidal flat is in the mesohaline part of the estuary (Van Damme et al. 2005). The tidal range varies from ca $3.81 \mathrm{~m}$ on neaps to $5.25 \mathrm{~m}$ on springs. Mean High Water Neap level at the Plaat van Walsoorden is $2.07 \mathrm{~m}$ above Dutch Ordnance Datum NAP. The tidal flat is composed of sandy to muddy sediment, inhabited by microphytobenthos and occasionally patches of the xanthophyte Vaucheria sp. (Van der Wal et al. 2008b). The highest part of the tidal flat has accreted for many years, facilitating salt marsh growth, which, in turn, favored siltation (Van der Wal et al. 2011). Colonization of this part of the mudflat started with establishment of tussocks of S. anglica (common cord grass) in the late 1980s (Temmerman et al. 2007). S. anglica was mostly replaced by the perennial A. tripolium (sea aster) in the past decade. In addition, $S$. procumbens establishes on the bare mudflat when elevation is sufficiently high, attaining a higher density and covering a greater area each year (cf. Fig. 2a, b). Both $S$. procumbens and A. tripolium also expanded 


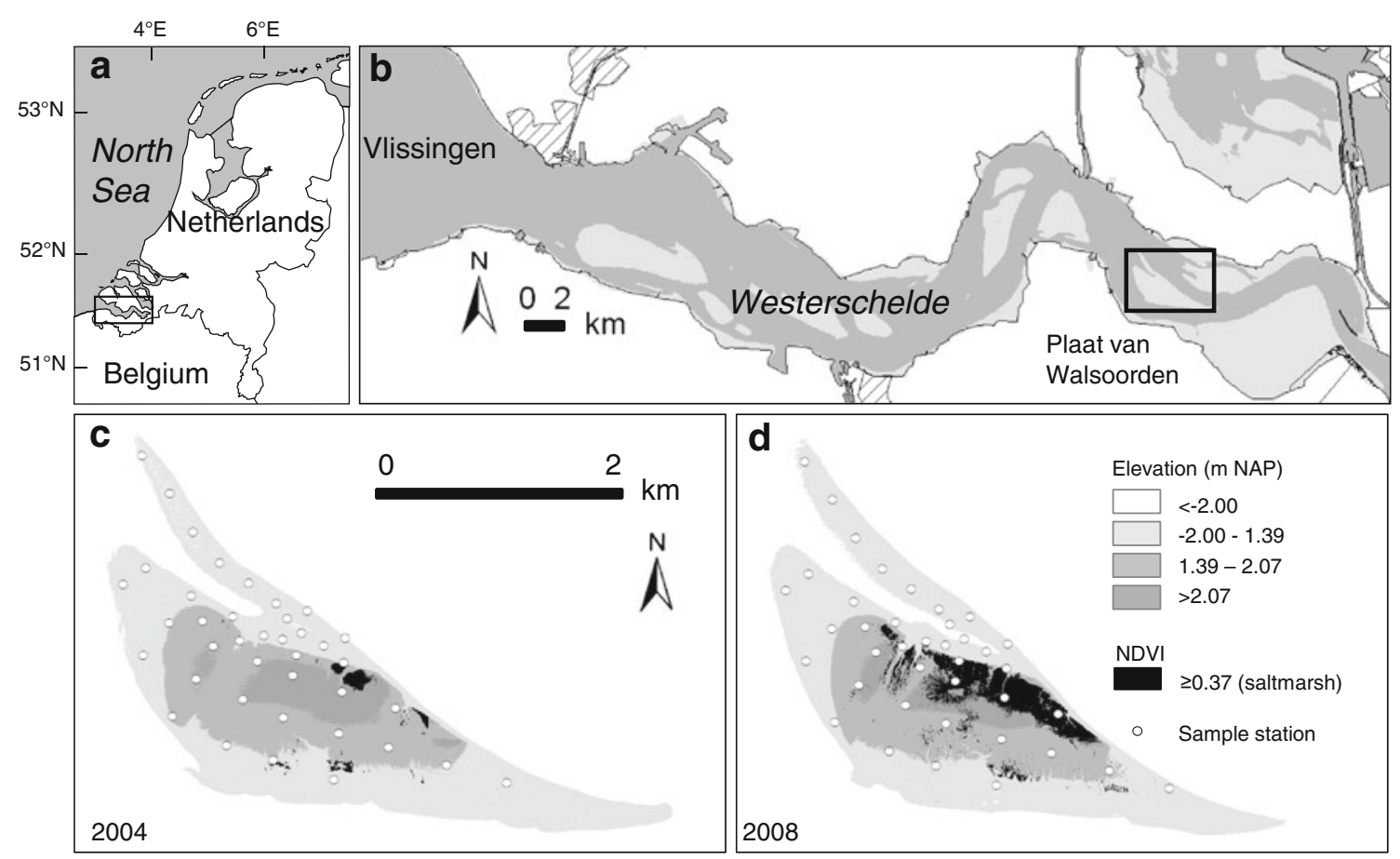

Fig. 1 (a) Westerschelde estuary, southwest Netherlands, with (b) the intertidal flat Plaat van Walsoorden. Elevation from airborne LIDAR surveys and superimposed salt marsh areas from airborne hyperspectral surveys are shown for $\mathbf{c} 2004$ and $\mathbf{d}$ 2008, along with the field stations for sampling

laterally into lower unvegetated areas, perhaps facilitated by the accretional regime. $S$. procumbens stands are also gradually being replaced by $A$. tripolium (cf. Fig. 2b, c). $S$. procumbens plants reach a height of $20-30 \mathrm{~cm}$ in height. A. tripolium plants are ca. $30-40 \mathrm{~cm}$ tall in spring and 30 $180 \mathrm{~cm}$ in autumn, while a large part of aboveground structure dies off or washes away during winter.

\section{Field Sampling and Laboratory Analysis}

In 2004-2008, benthic macrofauna was sampled both in spring (April/May) and autumn (August/September) on a fixed grid (determineded with a GPS) with 39 stations covering the entire intertidal flat (Fig. 1). At each station, three $8-\mathrm{cm}$ diameter cores were collected up to a depth of $30 \mathrm{~cm}$. The material of the three cores was pooled and sieved with a $1-\mathrm{mm}$ sieve. The material $>1 \mathrm{~mm}$ was stained and fixed in formaldehyde and used for analysis of macrofauna. Sediment samples for grain size analyses were collected from the upper $3 \mathrm{~cm}\left(20 \mathrm{~cm}^{3}\right)$ of the surface, and from 2006 onwards, additional sediment samples for pigment analyses were collected from the upper $1 \mathrm{~cm}\left(4 \mathrm{~cm}^{3}\right)$ of sediment using tip-cut syringes.

In the laboratory, all benthic invertebrates were picked out under a dissecting microscope, identified and counted at the species level (except for Collembola, Insecta, Mysidae, Nemertea, Nudibranchia, and Oligochaeta). The organisms were dried at $80^{\circ} \mathrm{C}$ for 2 days, then at $100^{\circ} \mathrm{C}$ for 1 day and then ashed for $2 \mathrm{~h}$ at $580^{\circ} \mathrm{C}$ to determine biomass (ash-free dry weight, in milligrams per square meter). Shannon (e base) taxon diversity index $H^{\prime}$ was calculated for each sample from density (number of individuals per square meter) data of the taxa (Gray and Elliot 2009) using the software package PRIMER (Plymouth Marine Laboratory). In addition, the quotient (in milligrams per individual) of total biomass and total density was calculated for each sample.

Sediment grain size samples were freeze-dried and material was analyzed using a Malvern laser particle sizer to derive median grain size of the sediment. Pigments were extracted by taking $1 \mathrm{~g}$ of homogenized sediment added to $10 \mathrm{ml} \mathrm{90 \%} \mathrm{acetone.} \mathrm{Mechanical} \mathrm{disruption} \mathrm{using} \mathrm{a} \mathrm{Bead}$ Beater ensured an efficient release of pigment. Extracts were quantified using high-performance liquid chromatography and pigments were identified by a comparison of peaks and retention times with available standards. Pigments were used to mark phylogenetic groups, including chlorophyll-a (Chl- $a$ ) for all oxygenic phototrophs, fucoxanthin for diatoms, zeaxanthin for cyanobacteria, and lutein for detritus of vascular plants (and green algae). The ratio of pigments was used to indicate dominance by phylogenetic groups (AbeleOeschger 1991; Barranguet et al. 1997). To account for differences in pigment ratios under different irradiance levels (Brotas and Plante-Cuny 2003), the zeaxanthin/fucoxanthin ratio was used as a measure of cyanobacterial abundance relative to diatoms (Janousek 2009). 

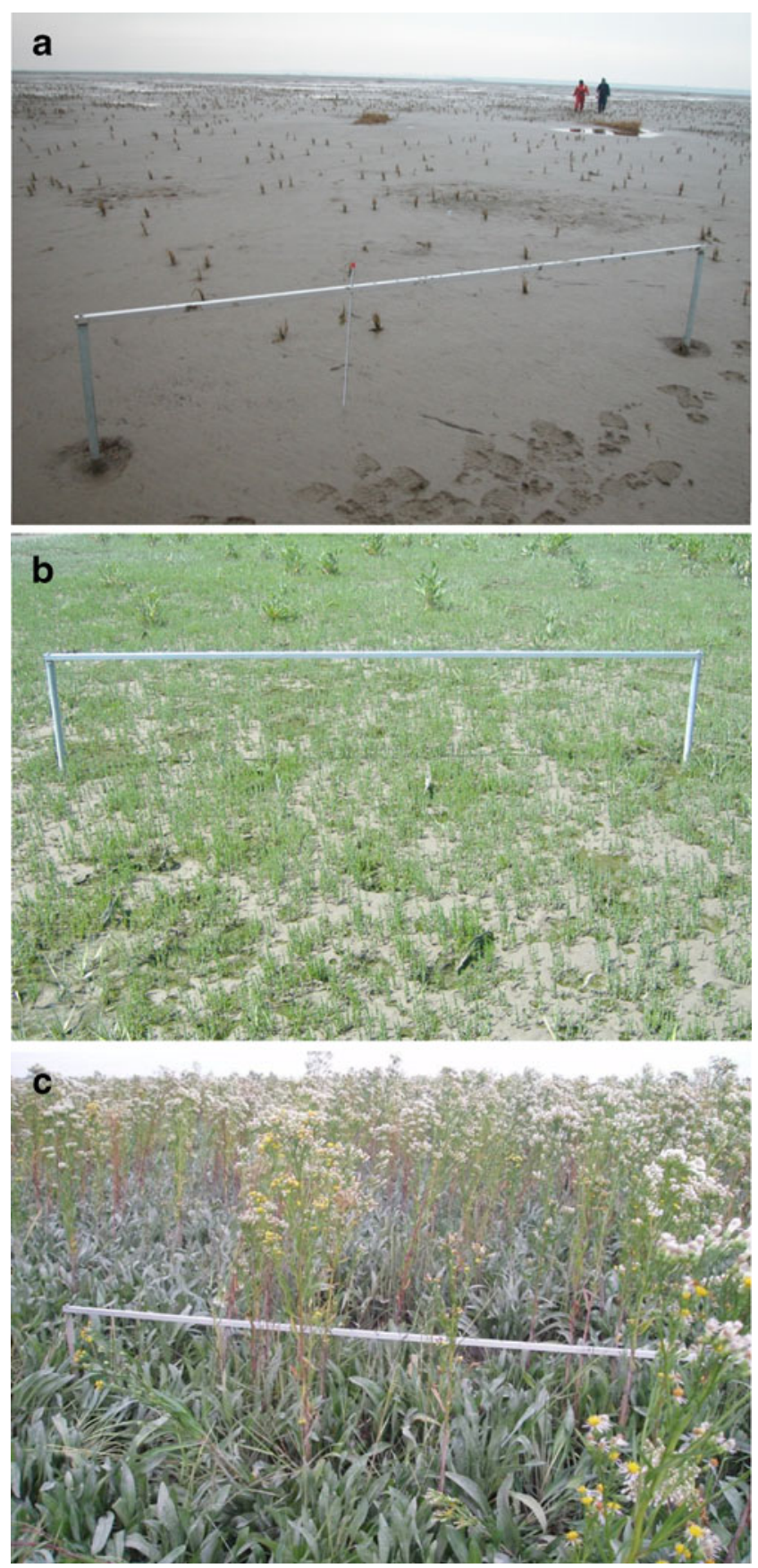

Fig. 2 Vegetation succession at a station: transition from a mudflat with very sparse Salicornia procumbens (photo January 2005) to b salt marsh with dense Salicornia procumbens and some Aster tripolium (photo June 2006) and c salt marsh with dense Aster tripolium cover (photo September 2007)

\section{Airborne Data}

Yearly maps of the vegetation index NDVI were derived from geocorrected and atmospherically corrected airborne hyperspectral images with a 2-4 m spatial resolution (Van der Wal et al. 2008b). NDVI was calculated using surface reflectance in the red $\left(R_{683 \mathrm{~nm}}\right)$ and near-infrared $\left(R_{866 \mathrm{~nm}}\right)$, i.e., $\mathrm{NDVI}=$
$\left(R_{866 \mathrm{~nm}}-R_{683 \mathrm{~nm}}\right) /\left(R_{866 \mathrm{~nm}}+R_{683 \mathrm{~nm}}\right)$. NDVI gives higher values with increasing biomass or cover of microphytobenthos, sporadically Vaucheria sp. and/or vascular plants (A. tripolium, S. procumbens, and S. anglica). The images were acquired in either June or August of each year. Despite these seasonal differences, NDVI $\geq 0.37$ was found to be representative for areas dominated by salt marsh plants. This was confirmed by ground photographs of the stations taken during sampling. The ground photos were also used to discriminate between dominance by A. tripolium or S. procumbens ( $S$. anglica did not dominate any of the cases) in each year. For each salt marsh case, marsh age was calculated from the sequential airborne surveys, indicating the number of years the salt marsh (NDVI $\geq 0.37$ ) existed at a station in the year of sampling.

Each summer, airborne Light Detection and Ranging (LIDAR) surveys acquired elevation, with 1-2 m spatial resolution and $\sim 0.05 \mathrm{~m}$ vertical accuracy $(1 \sigma)$. Validation with in situ dGPS measurements in June 2007 demonstrated that the LIDAR measurements were representative of sediment surface elevation.

\section{Statistical Analyses}

Analyses of macrobenthic biomass, density, and species diversity were performed in Statistica. Station samples for each year and season were treated as independent cases. Regression analysis was carried out to test the dependence of macrofaunal biomass, density, and diversity on continuous (abiotic and biotic) variables for cases with (NDVI $\geq 0.37$ ) and without (NDVI <0.37), salt marsh respectively, while ANOVA, followed by an a posteriori HSD Tukey test for unequal sample size, demonstrated effects of categorical predictors (such as vegetation type). A homogeneity-of-slopes test revealed whether median grain size and elevation had a different effect on macrofauna in salt marsh and unvegetated mudflats, respectively.

Macrobenthic community structure was analyzed using PRIMER (Clarke 1993). Analyses were done separately based on unstandardized, log-transformed biomass $\ln (x+1)$ and density $\ln (x+1)$ of the macrobenthic taxa, respectively. Rare taxa (i.e., occurring in only one sample) were eliminated to reduce the dimensionality of the dataset (from 65 taxa to 47). Five samples that contained no or only one species were omitted from the multivariate analysis; all belonged to the low elevation and coarse sediment cluster (no salt marsh).

Ordination (non-metric multidimensional scaling) plots of macrobenthic community structure were constructed based on Bray-Curtis similarity matrices (i.e., similarity between every pair of samples). A stress value between 0 and 1 ( $<0.2$ being useful) presented in each plot expressed 
how well the sample relationships were represented in the 2D ordination.

Non-parametric Spearman rank correlation analysis of the Bray-Curtis resemblance matrices (for log-transformed biomass and density, respectively) and a Euclidian distance matrix of normalized environmental and pigment data (BEST in PRIMER) identified which (combination of) environmental variables and (combination of) pigment variables best explained the macrobenthic community structure, respectively, with significance tested via a permutation approach.

Clusters were constructed based on median grain size and elevation, respectively. First, cases were ranked according to median grain size (Online Resource 1). Cases with salt marsh (NDVI $\geq 0.37$ ) were equally divided into clusters with medium-grained sediment $(0.140-0.204 \mathrm{~mm})$ and fine sediment (median grain size $<0.140 \mathrm{~mm}$ ). Based on median grain size, cases without salt marsh (NDVI $<0.37$ ) were also classified into these two clusters, or in the remaining cluster with coarse sediment (median grain size $>0.204 \mathrm{~mm}$ ). Then, cases were ranked according to elevation (Online Resource 2). The cases with salt marsh were split into two groups: the intermediate (elevation 1.39-2.07 m NAP) and high (elevation >2.07 m NAP, i.e., above Mean High Water Neap level, thus staying dry at neap tides) elevation cluster. Based on elevation, cases without salt marsh were also classified into these two clusters, or in the remaining cluster with low elevations (elevation $<1.39$ m NAP).

Significance of differences in macrobenthic community between clusters was formally tested using ANOSIM (analysis of similarities) in PRIMER. ANOSIM yields an $R$ value as a nonparametric measure of discrimination based on rank similarities between samples, tested via a permutation approach. $R$ values (for global effects and for each pairwise comparison of clusters) range from -1 to $1, R>0.5$ generally indicating clear separation between clusters. Similarity percentage (SIMPER) identified which taxa contributed most to the distinction of clusters. As similar results were obtained when the macrobenthic community of a random subset of cases in unvegetated areas was compared to that of all salt marsh cases, we did not account for the unequal sample size of the clusters in the multivariate analysis.

In all statistical analyses, samples from all years and seasons were pooled. In addition, separate analyses were carried out for samples collected in spring and autumn, respectively, to verify that effects persisted across seasons. The effect of year and station was tested using ANOVA with station as random factor. In all statistical tests, macrobenthic biomass, density, biomass/density, and pigments concentrations were $\log$-transformed following $\ln (x+1)$ to approach homogeneity of variance as well as a normal distribution within groups. A 5\% significance level was applied to all statistical tests.

\section{Results}

Factors Explaining Macrofaunal Biomass and Density and Taxon Diversity

Regression analyses revealed how the abiotic and biotic factors depended on macrobenthic biomass, density and diversity in unvegetated (Table 1) and vegetated areas (Table 2), respectively. In unvegetated areas, biomass, density, and diversity of the macrofauna increased with a decrease in median grain size and an increase in elevation (Table 1). In addition, a significant positive relationship was found for pigments (notably for Chl-a and fucoxanthin, indicators for diatoms). NDVI, which can be used as a proxy for microphytobenthic biomass in unvegetated areas, also showed a significant positive relationship with macrofauna.

In the salt marsh, relationships were generally not significant when Bonferroni-corrected, but macrofaunal biomass and taxon diversity increased with median grain size and macrobenthic density decreased with age of the salt marsh (Table 2). Signs of the slopes of the regressions were consistent for spring and autumn samples.

A covariance analysis (homogeneity-of-slopes test) confirmed the dual effect of median grain size on macrofauna (Table 3). The significant interaction term median grain size $\times$ salt marsh demonstrated that biomass, density, and taxon diversity decreased with median grain size in unvegetated areas, but increased with median grain size in vegetated areas (Fig. 3). Median grain size was also finer in salt marsh than in unvegetated areas. Furthermore, macrofaunal density decreased with median grain size (Table 3). A homogeneity-of-slopes test with elevation (Table 4; Fig. 4) demonstrated a significantly higher macrofaunal density and a significantly lower biomass per individual (and presumably, size of the individual) with elevation, while the effect of salt marsh and interaction effects elevation $\times$ salt marsh were not significant. Macrofaunal biomass, density, diversity, and biomass per individual did not differ between salt marsh and unvegetated mudflat when controlled for elevation. Note that median grain size and elevation were correlated for cases in unvegetated areas (Pearson product moment correlation coefficient $r=-0.612, P<0.001, n=362$ ), but not for the salt marsh cases ( $r=0.06, P=0.751, n=28)$.

In a main-effects ANOVA of station and year, with station as random factor, there was no significant effect of year on biomass, density, and taxon diversity $H^{\prime}$ (all $P>0.05$ ), whereas the station effect was significant (all $P<0.001$ ), suggesting that year-to-year variation in macrofauna did not significantly bias our analyses, whereas repeated measures of stations were not independent. The result was similar when the analysis was restricted to unvegetated mudflat cases only. In contrast, analysis for marsh cases only demonstrated that neither the effect of year nor station were 
Table 1 Linear regression analysis of log-transformed macrobenthic biomass, density, and taxon diversity $H^{\prime}$ as a function of biotic and abiotic variables for cases without salt marsh

\begin{tabular}{|c|c|c|c|c|c|c|c|c|c|c|c|c|c|c|c|}
\hline \multirow[t]{2}{*}{ Variable } & \multicolumn{5}{|c|}{$\ln ($ biomass +1$)$} & \multicolumn{5}{|c|}{$\ln ($ density +1$)$} & \multicolumn{5}{|l|}{$H^{\prime}$} \\
\hline & $F_{1, n-2}$ & $R^{2}$ & $n$ & $P$ & & $F_{1, n-2}$ & $R^{2}$ & $n$ & $P$ & & $F_{1, n-2}$ & $R^{2}$ & $n$ & $P$ & \\
\hline \multicolumn{15}{|l|}{ Abiotic } & \\
\hline Median grain size $(\mathrm{mm})$ & 225.56 & 0.39 & 362 & $<0.001^{*}$ & - & 262.75 & 0.42 & 362 & $<0.001^{*}$ & - & 65.06 & 0.15 & 362 & $<0.001^{*}$ & \\
\hline Elevation (m NAP) & 101.63 & 0.22 & 362 & $<0.001 *$ & + & 436.96 & 0.55 & 362 & $<0.001 *$ & + & 5.95 & 0.02 & 362 & $0.015^{*}$ & \\
\hline \multicolumn{15}{|l|}{ Pigments $\left(\mu \mathrm{g} \mathrm{g}^{-1}\right)$} & \\
\hline $\ln (\mathrm{Chl}-a+1)$ & 184.57 & 0.47 & 208 & $<0.001^{*}$ & + & 230.07 & 0.53 & 208 & $<0.001^{*}$ & + & 28.51 & 0.12 & 208 & $<0.001^{*}$ & \\
\hline $\ln ($ fucoxanthin +1$)$ & 167.34 & 0.45 & 208 & $<0.001 *$ & + & 191.23 & 0.48 & 208 & $<0.001 *$ & + & 27.09 & 0.12 & 208 & $<0.001 *$ & \\
\hline $\ln ($ lutein +1$)$ & 7.03 & 0.03 & 208 & $0.009^{*}$ & + & 7.98 & 0.04 & 208 & $0.005 *$ & + & 0.19 & 0.00 & 208 & 0.666 & \\
\hline $\ln ($ zeaxanthin +1$)$ & 26.48 & 0.11 & 208 & $<0.001 *$ & + & 40.82 & 0.17 & 208 & $<0.001 *$ & + & 10.82 & 0.05 & 208 & $0.001 *$ & \\
\hline \multicolumn{15}{|l|}{ Pigment ratios } & \\
\hline Fucoxanthin/Chl- $a$ & 10.43 & 0.05 & 206 & $0.001^{*}$ & + & 6.30 & 0.03 & 206 & $0.013^{*}$ & + & 2.85 & 0.01 & 206 & 0.093 & \\
\hline Lutein/Chl- $a$ & 8.43 & 0.04 & 206 & $0.004 *$ & + & 5.02 & 0.02 & 206 & $0.026^{*}$ & + & 0.23 & 0.00 & 206 & 0.632 & \\
\hline Zeaxanthin/Chl- $a$ & 36.41 & 0.15 & 206 & $<0.001^{*}$ & + & 61.16 & 0.23 & 206 & $<0.001 *$ & + & 9.26 & 0.04 & 206 & $0.003 *$ & \\
\hline Zeaxanthin/fucoxanthin & 20.58 & 0.10 & 185 & $<0.001^{*}$ & + & 37.79 & 0.17 & 185 & $<0.001^{*}$ & + & 6.14 & 0.03 & 185 & $0.014 *$ & \\
\hline NDVI & 140.44 & 0.28 & 362 & $<0.001^{*}$ & + & 165.77 & 0.32 & 362 & $<0.001 *$ & + & 47.41 & 0.12 & 362 & $<0.001 *$ & \\
\hline
\end{tabular}

Sign of the slope of significant regressions is shown

$F_{d f}$ Test statistic, $R^{2}$ coefficient of determination, $n$ number of cases, $* P<0.05$ Significance

significant (all $P>0.05$ ), suggesting that the salt marsh cases were independent in time and space with regard to macrofauna. Similarly, median grain size, pigments, and pigment ratios did not depend on year or station in the salt marsh (all $P>0.05$ ), whereas elevation depended both on year (highest elevation in 2006, lowest elevation in 2007) and station, and

Table 2 Linear regression analysis of log-transformed macrobenthic biomass, density, and taxon diversity $H^{\prime}$ as a function of biotic and abiotic variables for cases with salt marsh

\begin{tabular}{|c|c|c|c|c|c|c|c|c|c|c|c|c|c|c|}
\hline \multirow[t]{2}{*}{ Variable } & \multicolumn{5}{|c|}{$\ln ($ biomass +1$)$} & \multicolumn{5}{|c|}{$\ln ($ density +1$)$} & \multicolumn{4}{|l|}{$H^{\prime}$} \\
\hline & $F_{1, n-2}$ & $R^{2}$ & $n$ & $P$ & & $F_{1, n-2}$ & $R^{2}$ & $n$ & $P$ & & $F_{1, n-2}$ & $R^{2}$ & $n$ & $P$ \\
\hline \multicolumn{15}{|l|}{ Abiotic } \\
\hline Median grain size $(\mathrm{mm})$ & 4.31 & 0.14 & 28 & $0.048^{*}$ & + & 0.43 & 0.02 & 28 & 0.520 & & 7.33 & 0.22 & 28 & $0.012 *$ \\
\hline Elevation (m NAP) & 0.65 & 0.02 & 28 & 0.428 & & 1.34 & 0.05 & 28 & 0.258 & & 1.89 & 0.07 & 28 & 0.180 \\
\hline \multicolumn{15}{|l|}{ Pigments $\left(\mu \mathrm{g} \mathrm{g}^{-1}\right)$} \\
\hline $\ln (\mathrm{Chl}-a+1)$ & 0.08 & 0.00 & 23 & 0.782 & & 1.91 & 0.08 & 23 & 0.181 & & 0.00 & 0.00 & 23 & 0.982 \\
\hline $\ln ($ fucoxanthin +1$)$ & 0.04 & 0.00 & 23 & 0.852 & & 0.99 & 0.05 & 23 & 0.330 & & 0.29 & 0.01 & 23 & 0.598 \\
\hline $\ln ($ lutein +1$)$ & 0.39 & 0.02 & 23 & 0.541 & & 0.21 & 0.01 & 23 & 0.650 & & 0.37 & 0.02 & 23 & 0.551 \\
\hline $\ln ($ zeaxanthin +1$)$ & 0.19 & 0.01 & 23 & 0.664 & & 1.36 & 0.06 & 23 & 0.256 & & 0.68 & 0.03 & 23 & 0.421 \\
\hline \multicolumn{15}{|l|}{ Pigment ratios } \\
\hline Fucoxanthin/Chl- $a$ & 0.10 & 0.00 & 23 & 0.750 & & 1.71 & 0.08 & 23 & 0.205 & & 2.70 & 0.11 & 23 & 0.115 \\
\hline Lutein/Chl- $a$ & 0.22 & 0.01 & 23 & 0.646 & & 0.55 & 0.03 & 23 & 0.465 & & 0.22 & 0.01 & 23 & 0.643 \\
\hline Zeaxanthin/Chl- $a$ & 0.49 & 0.02 & 23 & 0.491 & & 1.23 & 0.06 & 23 & 0.279 & & 0.61 & 0.03 & 23 & 0.442 \\
\hline Zeaxanthin/fucoxanthin & 0.69 & 0.03 & 23 & 0.416 & & 2.34 & 0.10 & 23 & 0.141 & & 0.73 & 0.01 & 23 & 0.731 \\
\hline NDVI & 0.99 & 0.04 & 28 & 0.329 & & 2.63 & 0.09 & 28 & 0.117 & & 0.35 & 0.01 & 28 & 0.559 \\
\hline Marsh age (years) & 1.05 & 0.04 & 28 & 0.314 & & 4.57 & 0.15 & 28 & $0.042 *$ & - & 0.01 & 0.00 & 28 & 0.945 \\
\hline
\end{tabular}

Sign of the slope of significant regressions is shown

$F_{d f}$ Test statistic, $R^{2}$ coefficient of determination, $n$ number of cases, ${ }^{*} P<0.05$ Significance 
Table 3 Homogeneity-of-slopes test of the macrobenthic measures as a function of (continuous variable) median grain size and categorical predictor salt marsh and their interaction term, with number of cases $n$, and test statistic $F_{d f}$ and significance $P$ for each effect

\begin{tabular}{|c|c|c|c|c|c|c|c|}
\hline \multirow[t]{2}{*}{ Macrobenthos } & \multirow[t]{2}{*}{$n$} & \multicolumn{2}{|c|}{ Median grain size } & \multicolumn{2}{|c|}{ Marsh } & \multicolumn{2}{|c|}{ Median $\times$ marsh } \\
\hline & & $F_{1, n-4}$ & $P$ & $F_{1, n-4}$ & $P$ & $F_{1, n-4}$ & $P$ \\
\hline $\ln ($ biomass +1$), \mathrm{mg} \mathrm{m}^{-2}$ & 390 & 2.51 & 0.114 & 41.69 & $<0.001 *$ & 32.68 & $<0.001^{*}$ \\
\hline $\ln ($ density +1$)$, ind $\mathrm{m}^{-2}$ & 390 & 9.72 & $0.002 *$ & 22.09 & $<0.001 *$ & 21.59 & $<0.001^{*}$ \\
\hline $\ln ($ biomass/density +1$), \mathrm{mg} \mathrm{ind}^{-1}$ & 388 & 2.52 & 0.113 & 2.60 & 0.108 & 1.24 & 0.267 \\
\hline Taxon diversity $H^{\prime}$ & 390 & 0.53 & 0.466 & 32.02 & $<0.001 *$ & 21.64 & $<0.001 *$ \\
\hline
\end{tabular}

$* P<0.05$ significant effects

NDVI depended both on year (gradual increase in NDVI) and on station (all $P<0.01$ ).

Vegetation type (S. procumbens versus A. tripolium) did not have a significant effect on the biomass (one-way ANOVA, $F_{1,26}=0.13, P=0.725, n=28$ ) or on taxon diversity $H^{\prime}\left(F_{1,26}=0.73, P=0.400, n=28\right)$, but macrofaunal density was significantly lower in $A$. tripolium than in $S$. procumbens stands $\left(F_{1,26}=5.38, P=0.028, n=28\right)$.

A one-way ANOVA and posthoc Tukey test for unequal sample sizes revealed that $S$. procumbens occurred, on average, at higher elevations than A. tripolium $\left(F_{1,26}=8.41\right.$, $P=0.007, n=28)$, but they were associated with similar grain size $\left(F_{1,26}=3.26, P=0.083, n=28\right)$. In addition, $A$. tripolium salt marsh was significantly older than $S$. procumbens salt marsh $\left(F_{1,26}=9.77, P=0.004, n=28\right)$ and had a significantly higher NDVI $\left(F_{1,26}=4.78, P=0.038, n=\right.$ 28 ), pointing to a more developed aboveground structure.

A linear regression of median grain size $\left(R^{2}=0.02, F_{1,26}=\right.$ $0.51, P=0.483, n=28)$ and elevation $\left(R^{2}=0.01, F_{1,26}=0.22\right.$, $P=0.640, n=28)$ on marsh age did not reveal a significant dependence. In contrast, NDVI significantly depended on marsh age $\left(R^{2}=0.48, F_{1,26}=0.24, P<0.001, n=28\right)$, confirming an increase in aboveground plant cover with salt marsh age. None of the pigments or pigment ratios depended significantly on marsh age (all $P>0.05$, e.g., $R^{2}=0.01, \quad F_{1,21}=0.223, \quad P=0.641, \quad n=23$ for $\left.\mathrm{Chl}-a\right)$ or NDVI (all $P>0.05$, e.g., $R^{2}=0.04, F_{1,21}=0.96, P=0.338$, $n=23$ for Chl-a), suggesting that accumulation of plant
Fig. 3 Macrobenthic a biomass, b density, c biomass per density, and $\mathbf{d}$ taxon diversity $H^{\prime}$ as a function of median grain size. Black symbols and regression lines are based on cases without salt marsh and gray symbols and regression lines are based on cases with salt marsh. Vertical lines show means \pm standard error of equally sized classes in unvegetated areas and in the salt marsh, respectively; horizontal lines show the range of these classes. Details of the regressions are given in Tables 1, 2, and 3 a

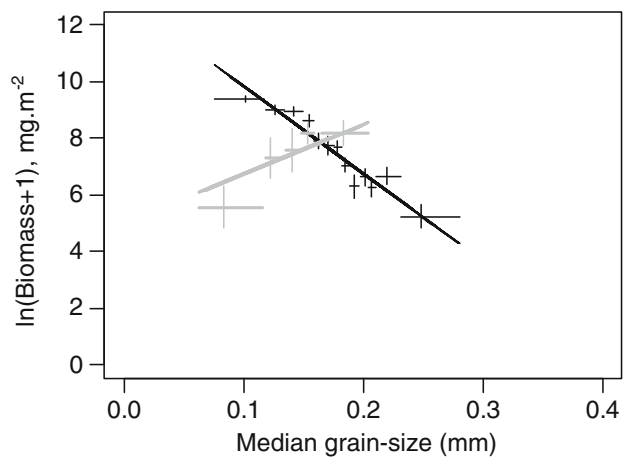

C

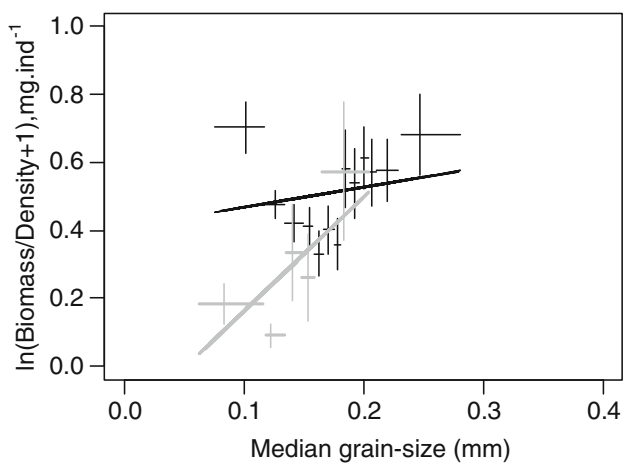

b

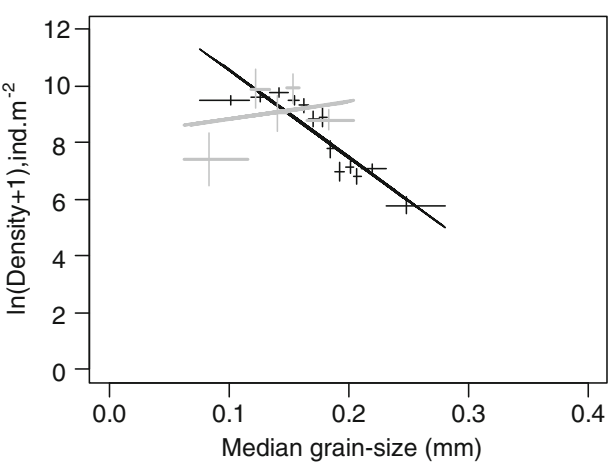

d

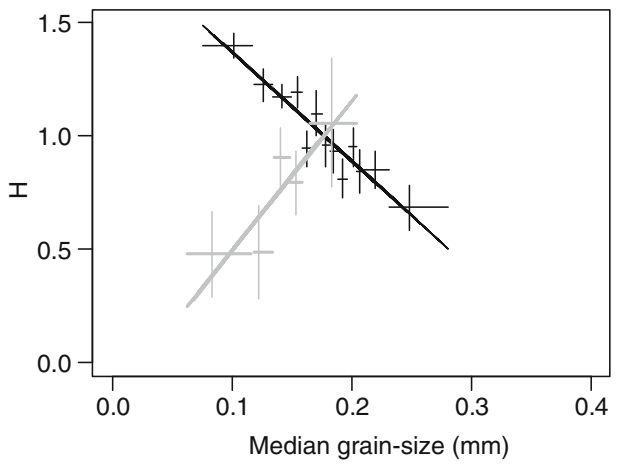


Table 4 Homogeneity-of-slopes test of the macrobenthic measures as a function of (continuous variable) elevation and categorical predictor salt marsh and their interaction term, with number of cases $n$, and test statistic $F_{d f}$ and significance $P$ for each effect

\begin{tabular}{|c|c|c|c|c|c|c|c|}
\hline \multirow[t]{2}{*}{ Macrobenthos } & \multirow[t]{2}{*}{$n$} & \multicolumn{2}{|c|}{ Elevation } & \multicolumn{2}{|l|}{ Marsh } & \multicolumn{2}{|c|}{ Elevation $\times$ marsh } \\
\hline & & $F_{1, \mathrm{n}-4}$ & $P$ & $F_{1, \mathrm{n}-4}$ & $P$ & $F_{1, \mathrm{n}-4}$ & $P$ \\
\hline $\ln ($ biomass +1$), \mathrm{mg} \mathrm{m}^{-2}$ & 390 & 0.017 & 0.897 & 1.07 & 0.302 & 0.29 & 0.091 \\
\hline $\ln ($ density +1$)$, ind $\mathrm{m}^{-2}$ & 390 & 11.30 & $0.001 *$ & 0.06 & 0.800 & 0.09 & 0.760 \\
\hline $\ln ($ biomass/density +1$), \mathrm{mg} \mathrm{ind}^{-1}$ & 388 & 8.09 & $0.005^{*}$ & 1.29 & 0.256 & 1.27 & 0.261 \\
\hline Taxon diversity $H^{\prime}$ & 390 & 0.15 & 0.229 & 0.93 & 0.336 & 2.70 & 0.101 \\
\hline
\end{tabular}

$* P<0.05$ significant effects

detritus (i.e., lutein) did not increase with marsh age and that microphytobenthos was not limited by shading effects of the plant canopy.

\section{Factors Explaining Macrofaunal Species Composition}

A correlation analysis of the continuous variables with the multivariate macrofaunal community structure revealed that a combination of median grain size and elevation best explained macrofaunal composition in unvegetated areas, both based on biomass of macrofaunal taxa (BEST in PRIMER, Spearman rank correlation $\rho=0.403, P=0.01$ ) and on density of macrofaunal taxa $(\rho=0.455, P=0.01)$. Of the microphytobenthic and pigment ratios, Chl- $a$ correlated best with macrobenthic community structure in unvegetated areas, both for biomass $(\rho=0.377, P=0.01)$ and density $(\rho=0.416, P=0.01)$ of the macrofauna.

In the salt marsh, the combination of median grain size and elevation also best explained the macrobenthic community, both for biomass $(\rho=0.214, P=0.01)$ and density $(\rho=0.267$, $P=0.01)$. Best correlations with pigments and pigment ratios for salt marsh cases were found for lutein/Chl- $a$, likely indicative of vascular plant detritus. It contributed significantly to explaining the density $(\rho=0.250, P=0.01)$ of the macrobenthic community, but not the biomass $(\rho=0.151$, $P=0.12$ ). NDVI from airborne surveys did not explain macrobenthic community within the salt marsh, neither for biomass $(\rho=-0.050, P=0.720)$ nor density $(\rho=-0.112$,
Fig. 4 Macrobenthic (a) biomass, (b) density, (c) biomass per density, and (d) taxon diversity $H^{\prime}$ as a function of elevation. Black symbols and regression lines are based on cases without salt marsh and gray symbols and regression lines are based on cases with salt marsh. Vertical lines show means \pm standard error of equally sized classes in unvegetated areas and in the salt marsh, respectively; horizontal lines show the range of these classes. Details of the regressions are given in Tables 1, 2, and 4
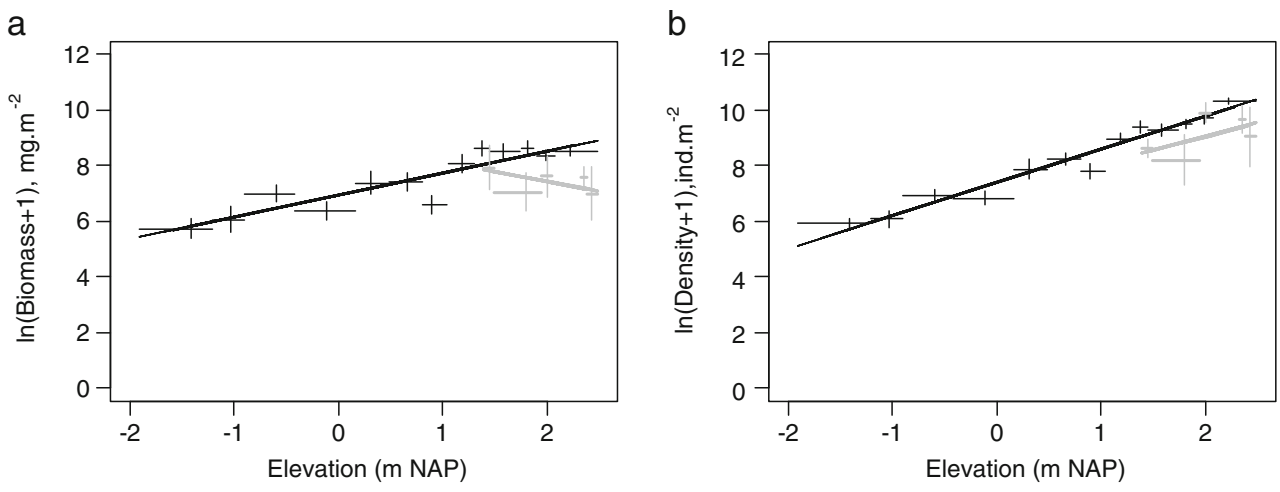

C

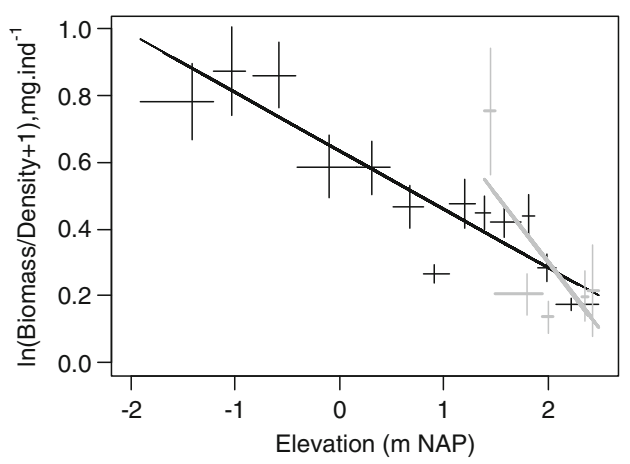

d

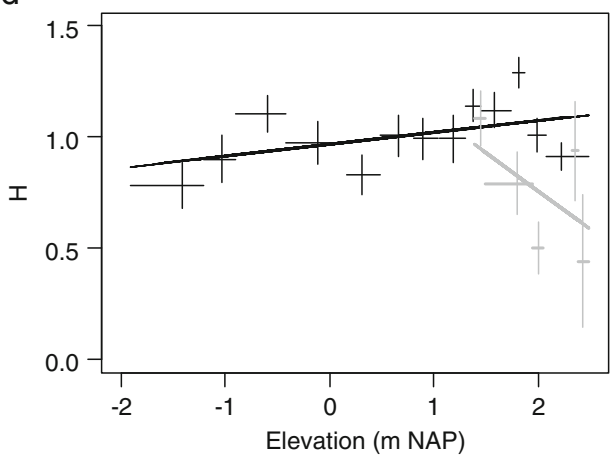


$P=0.920)$ of macrobenthos. Marsh age also did not significantly explain macrofaunal biomass $(\rho=0.015, P=0.340)$ or density $(\rho=0.024, P=0.330)$.

Salt marsh cases dominated by $A$. tripolium and by $S$. procumbens, respectively, $\operatorname{did}$ not accommodate a different macrobenthic community, whether the multivariate analysis was based on macrobenthic biomass (ANOSIM, $R=-0.034, P=0.630$, dissimilarity Diss $=62.23 \%$ ), or density (ANOSIM, $R=0.008, P=0.392$, Diss $=55.64 \%$ ).

\section{Macrofaunal Species Composition in Different Clusters}

The species composition of the macrofauna (based on biomass of taxa) in the five sediment grain size groups (fine, medium, and coarse sediment in unvegetated areas and fine and medium-grained sediment in salt marshes, see Online Resource 1) differed significantly (ANOSIM, global $R=0.243, P=0.001$; Fig. 5; Online Resource 3). In unvegetated areas, the macrofaunal community in medium and fine sediments did not differ significantly $(R=0.007, P=0.398$, Diss $=65.07 \%$ ), but there were significant differences in the community between medium and coarse sediment $(R=0.233, P=0.001$, Diss $=75.04 \%)$ and between fine and coarse sediment $(R=0.600, P=0.001$, Diss $=84.16 \%)$. While

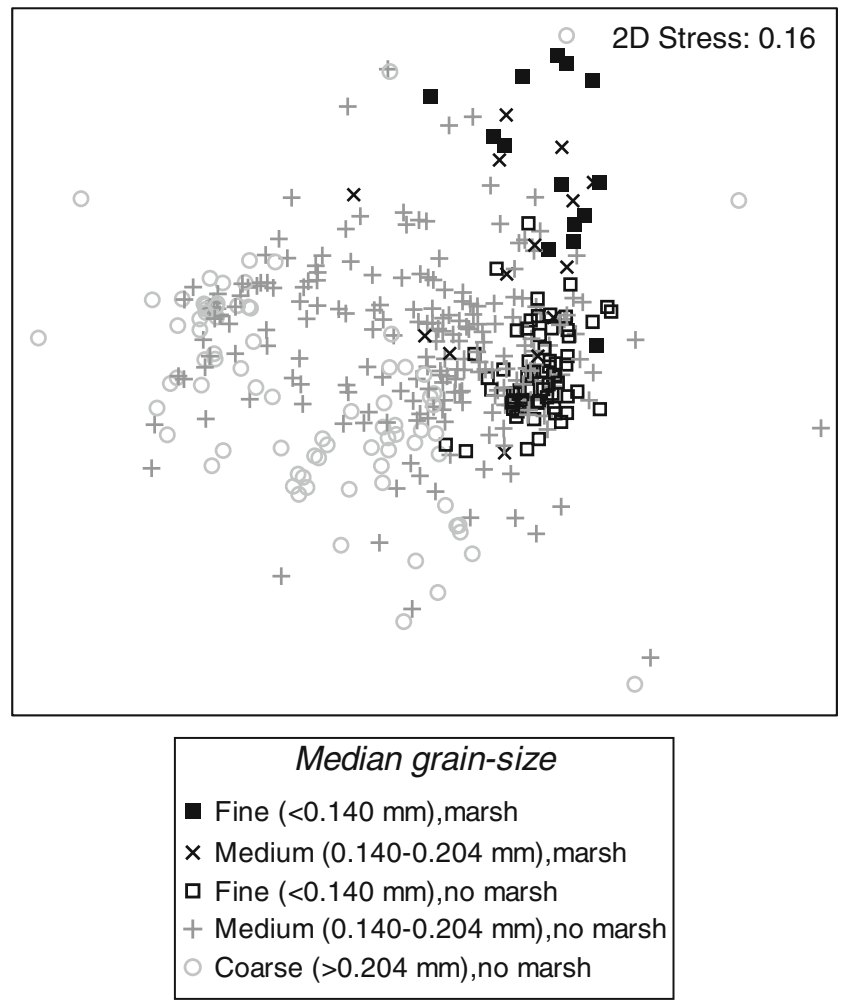

Fig. 5 nMDS plot of the macrobenthic community without and with salt marsh for fine (median grain size $<0.140 \mathrm{~mm}$ ), medium (median grain size $0.140-0.204 \mathrm{~mm}$ ) and coarse (median grain size $>0.204 \mathrm{~mm}$ ) sediments the within-group similarity of the unvegetated coarse sediment communities was mainly characterized by Bathyporeia pilosa and Macoma balthica, the medium and fine sediment groups were richer, with Heteromastus filiformis, Nereis diversicolor, and Pygospio elegans dominating mediumsized sediments and $N$. diversicolor, $P$. elegans and Corophium arenarium characterizing fine unvegetated sediments (SIMPER; Online Resource 3). In the salt marsh, differences in macrofaunal species composition in fine and medium-grained sediment were significant $(R=0.116$, $P=0.036$, Diss $=64.33 \%$ ), although overlap in species between the two salt marsh groups was high. Oligochaeta contributed $37.5 \%$ to the similarity within the mediumgrain size cluster, and $66.21 \%$ to the similarity within the fine sediment cluster, with $P$. elegans further contributing to the similarity within the medium-sized sediment (SIMPER; Online Resource 3). Fine sediments in the salt marsh had a lower biomass of $N$. diversicolor, P. elegans, and M. balthica and a higher biomass of Corophium volutator and Oligochaeta than medium-sized sediments in the salt marsh (SIMPER). Differences in community between vegetated and unvegetated areas were small in medium-sized sediment ( $R=0.165, P=0.021$, Diss $=72.60 \%$ ), but pronounced in fine sediment $(R=0.848, P=0.001$, Diss=77.65\%). In the medium-sized sediment, the difference could be attributed to a higher biomass of Oligochaeta and $N$. diversicolor, a lower biomass of M. balthica and B. pilosa, and a higher biomass of $C$. volutator and $P$. elegans in the salt marsh (SIMPER). In the fine sediment, the difference in macrobenthic community was due to a lower biomass of $N$. diversicolor, $H$. filiformis, and $M$. balthica, a higher biomass of Oligochaeta and a lower biomass of P. elegans in the salt marsh (SIMPER). Pronounced differences (ANOSIM, $R>0.500, P<0.05$ ) between groups persisted across seasons. For example, differences in the macrofaunal community between unvegetated and vegetated areas with fine sediments were significant both in autumn $(R=0.851$, $P=0.001$, Diss $=75.09 \%)$ and spring $(R=0.826, P=0.001$, Diss $=77.34 \%$ ), while those in medium-sized sediments were significant in spring $(R=0.223, P=0.025$, Diss $=$ $74.27 \%)$, but not in autumn $(R=0.052, \quad P=0.303$, Diss $=67.80 \%$ ).

The five elevation groups (high, intermediate, and low elevation in unvegetated areas; high and intermediate elevation in salt marsh, see Online Resource 2) had a significantly different macrobenthic community (ANOSIM, global $R=0.111$, $P=0.001$; Fig. 6; Online Resource 4). In unvegetated areas, there was, however, a large overlap in species for the intermediate versus the low-elevation cluster $(R=0.093, P=$ 0.001 , Diss $=72.38 \%$ ), while differences in community between the medium- and high-elevation cluster $(R=0.063$, $P=0.096$, Diss $=52.89 \%)$ and between the low- and highelevation cluster $(R=0.031, P=0.227$, Diss $=72.38 \%)$ were 


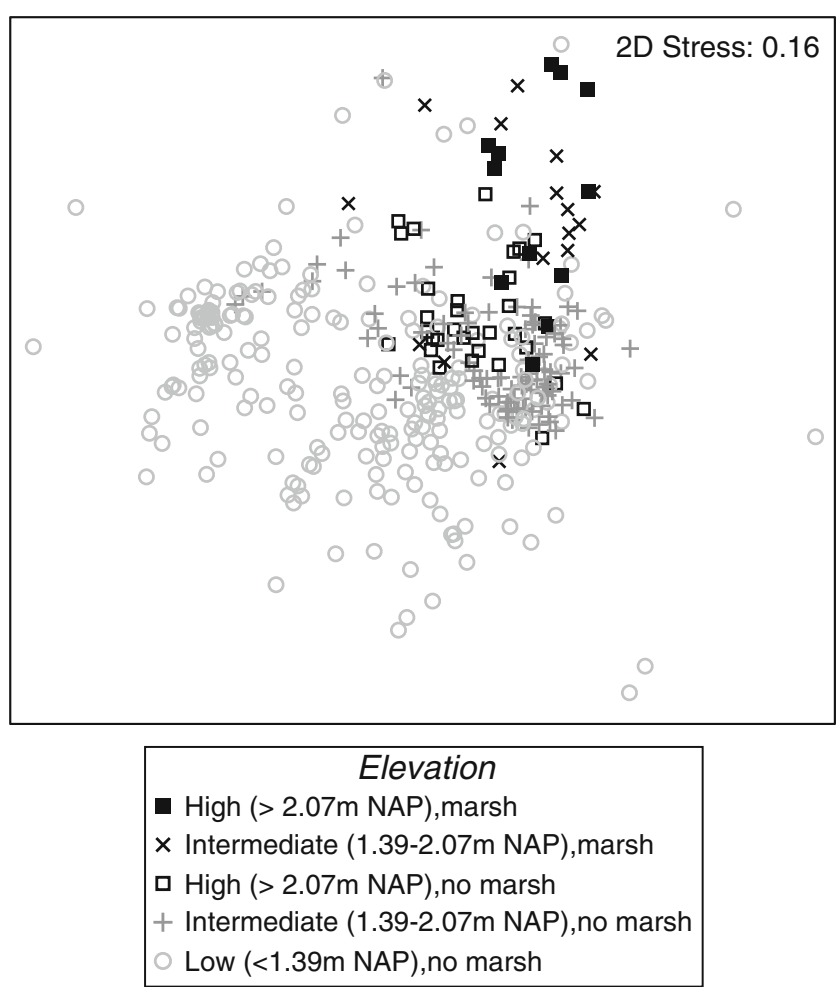

Fig. 6 nMDS plot of the macrobenthic community without and with salt marsh for high ( $>2.07 \mathrm{~m} \mathrm{NAP})$, intermediate (1.39-2.07 m NAP) and low $(<1.39$ m NAP) elevation

not significant. In the salt marsh, there were also no significant differences in macrofaunal community in the high and intermediate elevation cluster $(R=-0.025, \quad P=0.625$, Diss $=62.35 \%$ ). The differences in macrobenthic community between vegetated and unvegetated areas were more pronounced, both for intermediate elevation $(R=0.519$, $P=0.001$, Diss $=71.90 \%)$ and high elevation $(R=0.608$, $P=0.001$, Diss $=67.46 \%$ ). At intermediate elevation, the salt marsh had a lower biomass of $N$. diversicolor and $H$. filiformis, a higher biomass of $C$. volutator, a lower biomass of M. balthica, a higher biomass of Oligochaeta and a lower biomass of $P$. elegans than in unvegetated areas (SIMPER). At high elevation, the salt marsh had a lower biomass of Corophium arenarium, $N$. diversicolor, and $P$. elegans, a higher biomass of Oligochaeta and a lower biomass of $B$. pilosa and Hydrobia ulvae than in unvegetated areas (SIMPER). These differences between unvegetated and vegetated areas in intermediate and high elevation, respectively, were persistent across seasons (ANOSIM, $R>0.500$, $P<0.05$ for spring and autumn).

Very similar results were found when the analyses were based on density rather than biomass of the taxa in the macrobenthic community, both for the effect of median grain size (Online Resource 5) and elevation (Online Resource 6), although the results reflect the fact that the large species $N$. diversicolor and Macoma balthica, as well as $H$. filiformis contributed most to total macrofaunal biomass, while $P$. elegans, Oligochaeta, and $H$. filiformis contributed most to total macrofaunal density. The 11 taxa presented in the Electronic Supplementary Material comprised $>85 \%$ of both total macrofaunal density and biomass.

\section{Discussion}

Understanding the effect of salt marsh plants on macrobenthic fauna requires knowledge of the physical and biological forces that structure intertidal macrozoöbenthos communities. We tested whether macrofauna changed with sediment characteristics and elevation in a similar way in vegetated and unvegetated areas. Along a gradient towards higher elevations, higher emersion duration, lower levels of hydrodynamic stress, less sediment disturbance, finer sediment, higher levels of desiccation stress, higher microalgal abundance, less feeding time for most benthic invertebrates, and changes in predation pressure and competition are expected (e.g., Van Colen et al. 2010). In the present study, median grain size and elevation significantly explained the macrofaunal community in the absence of salt marsh plants. The elevation gradient was associated with a pronounced increase in particularly macrofaunal density and a decrease in organism size, ranging from a community dominated by the mobile amphipod B. pilosa and the bivalve $M$. balthica at low elevation and coarse sediment to a community with more species at higher elevations with finer sediments, with some evidence of a reduction of abundance of some species at the highest elevation levels (e.g., H. filiformis). In the salt marsh, biomass and density of Polychaeta, such as $N$. diversicolor, H. filiformis, and P. elegans and bivalves such as $M$. balthica were reduced, while the biomass and density of Oligochaeta increased, compared to unvegetated mudflats at comparable elevation. However, number of stations in the salt marsh was small. Effects of elevation on total macrofaunal biomass, density, and taxon diversity were not significant in the salt marsh. The shift in macrobenthic community and reduction in total biomass and taxon diversity in salt marshes appeared to be notably associated with fine sediments, while fine sediments in unvegetated areas accommodated maximum macrobenthic biomass and taxon diversity.

The dominance of Oligochaeta in the salt marsh was also found in earlier studies in temperate and arid salt marshes worldwide (Jackson et al. 1985; Talley and Levin 1999; Craft and Sacco 2003; Hampel et al. 2009; Wang et al. 2010). Oligochaeta can reach high abundances in salt marshes, as they can live in the microhabitat created by the root system of the plants and are capable of feeding upon plant detritus (Levin et al. 2006). 
Note that our study was based on macrofauna $>1 \mathrm{~mm}$, whereas many studies in salt marshes have used smaller sieve sizes $(0.250$ or $0.500 \mathrm{~mm})$ to sample benthic invertebrates. Comparison of results with studies using different mesh sizes (and different core depths) is difficult. In the study area, the benthic invertebrates $<1 \mathrm{~mm}$ are expected to be dominated by Oligochaeta, Nematoda, and small and juvenile Polychaeta and Crustacea, such as C. volutator (Ysebaert et al. 2005). Owing to their small size, they generally make up only a small part of the biomass of benthic invertebrates (Reise et al. 1994), but notably Oligochaeta can constitute a significant part of total abundance. In the present study, taxon diversity $H^{\prime}$ will have been affected by the fact that the Oligochaeta in particular were not identified to species level, while Polychaeta, Bivalvia, Gastropoda, and Crustacea were generally determined at the species level. However, the difference may have been small. Seys et al. (1999) found only two species of Oligochaeta (i.e., the tubificids Tubificoides heterochaetus and Heterochaeta costata) in the brackish zone of the Schelde (somewhat upstream of our study site) with on average only one species per sample.

We hypothesized that with salt marsh development, vegetation cover would increase, resulting in finer sediment with fewer diatoms and more plant detritus. We expected that macrofauna would have a significant response to both salt marsh age and vegetation cover. We did not find a significant effect of marsh age, vegetation cover, or dominant plant species on macrofaunal biomass, diversity and community structure (and indeed not on median grain size, diatom availability, or lutein/Chla contents), but there was a significant negative relationship between marsh age and macrofaunal density. In addition, total macrofaunal density was lower in A. tripolium than in S. procumbens. The lower elevation and denser foliage in A. tripolium, but particularly the greater age of the A. tripolium marsh likely tipped the balance towards a significantly lower macrofaunal density in these salt marshes. The older stands of the perennial $A$. tripolium may also have a denser root structure, inhibiting burrowing by larger macrofaunal species such as $N$. diversicolor.

Several studies reported a reduction of light under the canopy of $S$. foliosa and $S$. virginica marshes relative to unvegetated mudflats, resulting in a lower abundance of microalgae and a subsequent decline in surface deposit feeders, while subsurface feeding groups such as tubificid oligochaetes and capitellid polychaetes were less affected (Lana and Guiss 1992; Levin et al. 2006; Neira et al. 2007; Whitcraft and Levin 2007). In our study, we found no evidence that dominance of diatoms (here sampled from the upper $1 \mathrm{~cm}$ of sediment) was less in salt marsh than in unvegetated mudflats (Online Resources 1 and 2). In addition, we did not observe a decrease in diatom dominance with marsh age or NDVI. This suggests that (spring) blooms of diatoms could occur even in well-established salt marsh. Furthermore, pigment concentrations and ratios did not correlate with total macrobenthic biomass, density, and species diversity within the salt marsh. Moreover, some of the surface deposit feeders, particularly the mud shrimp, $C$. volutator, were not reduced in biomass or density.

Salt marshes may provide a refuge for resident fauna by protecting them from predation or abiotic stresses such as desiccation (Rader 1984; Lana and Guiss 1991; Hedge and Kriwoken 2000; Brusati and Grosholz 2006; Catrijsse and Hampel 2006; Neira et al. 2006; Bouma et al. 2009). Such positive effects of aboveground plant biomass on benthic macrofauna were not evident from our study. In our core samples, epifauna (dominated by the gastropod Hydrobia ulvae) was not abundant. However, larger invertebrate epifauna (such as shrimps and crabs) were certainly undersampled with the coring methods used (Angradi et al. 2001), while vertebrate predators, such as fish and birds, were not sampled at all in the present study. Therefore, we could not establish differences in predation pressure between habitats and potential changes in the relative importance of epifauna.

Trapping of sediment by salt marsh plants, such as Salicornia spp. and A. tripolium (Boorman et al. 2001) and Spartina spp. (Neumeier and Amos 2006) may not only result in accretion of fine sediments, but also in a more organic rich mud with limited oxygen penetration and increased pore water sulfide concentrations (Gribsholt and Kristensen 2003; Neira et al. 2006). Increased microbial activity associated with benthic algae and decaying plant material in the salt marsh may contribute to this reduced oxygen availability (Ponnamperuma 1972; Levin and Talley 2000). Indeed, lutein/Chl-a, a proxy for plant detritus, significantly explained the macrobenthic composition in the salt marsh based on species abundance. In fine-grained marsh sediments, Polychaeta, such as $N$. diversicolor, and to some extent also H. filiformis and P. elegans, had lower biomass and abundance in favor of Oligochaeta, which have a shallower burying depth and a smaller size (and thus higher surface area to body volume), making them better adapted to hypoxic environments (Seys et al. 1999; Chen et al. 2007). The limited abundance of large bioturbators such as $N$. diversicolor (perhaps also hindered by the root structure of the marsh) may have caused further changes in the geochemical properties of such salt marsh sediments (Gribsholt and Kristensen 2003; Van Wesenbeeck et al. 2007). This feedback loop may explain the low macrofaunal diversity in fine sediments in the salt marsh compared to unvegetated mudflats.

In conclusion, S. procumbens and A. tripolium stands accommodated a different macrobenthic assemblage than unvegetated mudflats, associated with a lower abundance 
of polychaetes and a higher abundance of oligochaetes. The lower abundance of macrofauna in salt marshes was especially noticeable in fine, muddy sediments, demonstrating a conditional effect of salt marsh plants on macrozoobenthos. The exact mechanisms underlying these findings remain to be established, for example by field or mesocosm experiments in a controlled and balanced design. Our observations suggest, however, that mechanical hindering of macrofaunal burrrowing by roots, as well as organic enrichment of the sediment, were the most plausible mechanisms for the influence of salt marsh plants on macrofauna.

Acknowledgments Data collection for this paper was funded by the Flemish Government, as part of the ecological evaluation of a dredged sediment relocation pilot in the Westerschelde, guided by S.J. Ides and Y. M.G. Plancke (Flanders Hydraulics Research) and F. Roose and A. Govaerts (Maritime Access Division). We would like to thank all involved in data collection and laboratory analysis, including R. Forster, F. Rossi, L. van IJzerloo, B. Koutstaal, A. Koutstaal, J. van Soelen, A. Wielemaker-van den Dool, and the crew of the RV Luctor, as well as T. Ysebaert, T. Bouma and A. Huiskes. Macrofauna was collected and identified by the Monitor Taskforce of the Netherlands Institute of Ecology, supervised by H. Hummel. LIDAR surveys were performed by Eurosense and Rijkswaterstaat. Hyperspectral airborne surveys were mainly acquired and atmospherically and geometrically corrected by E. Knaeps and D. Raymaekers of the Flemish Institute for Technological Research (VITO-TAP). We would like to thank the reviewers and the editors for their valuable suggestions and constructive remarks on an earlier version of this manuscript. This is publication number 5132 of the Netherlands Institute of Ecology (NIOO-KNAW).

Open Access This article is distributed under the terms of the Creative Commons Attribution Noncommercial License which permits any noncommercial use, distribution, and reproduction in any medium, provided the original author(s) and source are credited.

\section{References}

Abele-Oeschger, D. 1991. Potential of some carotenoids in two recent sediments of Kiel Bight as biogenic indicators of phytodetritus. Marine Ecology Progress Series 70: 83-92.

Angradi, T.R., S.M. Hagan, and K.W. Able. 2001. Vegetation type and the intertidal macroinvertebrate fauna of a brackish marsh: Phragmites vs. Spartina. Wetlands 21: 75-92.

Barranguet, C., P.M.J. Herman, and J.J. Sinke. 1997. Microphytobenthos biomass and community composition studied by pigment biomarkers: Importance and fate in the carbon cycle of a tidal flat. Journal of Sea Research 38: 59-70.

Boorman, L.A., J. Hazelden, and M. Boorman. 2001. The effect of rates of sedimentation and tidal submersion regimes on the growth of salt marsh plants. Continental Shelf Research 21: $2155-2165$.

Bouma, T.J., M.B. De Vries, E. Low, G. Peralta, C. Tanczos, J. Van de Koppel, and P.M.J. Herman. 2005. Trade-offs related to ecosystem engineering: A case study on stiffness of emerging macrophytes. Ecology 86: 2187-2199.

Bouma, T.J., V. Ortells, and T. Ysebaert. 2009. Comparing biodiversity effects among ecosystem engineers of contrasting strength: Macrofaunal diversity in Zostera noltii and Spartina anglica vegetations. Helgoland Marine Research 63: 3-18.
Brotas, V., and M.R. Plante-Cuny. 2003. The use of HPLC pigment analysis to study microphytobenthos communities. Acta Oecologica 24: S109-S115.

Bruno, J.F., J.J. Stachowicz, and M.D. Bertness. 2003. Inclusion of facilitation into ecological theory. Trends in Ecology \& Evolution 18: 119-125.

Brusati, E.D., and E.D. Grosholz. 2006. Native and introduced ecosystem engineers produce contrasting effects on estuarine communities. Biological Invasions 8: 683-695.

Catrijsse, A., and H. Hampel. 2006. European intertidal marshes: A review of their habitat functioning and value for aquatic organisms. Marine Ecology Progress Series 324: 293-307.

Chen, H., B. Li, J. Hu, J. Chen, and J. Wu. 2007. Effects of Spartina alterniflora invasion on benthic nematode communities in the Yangtze Estuary. Marine Ecology Progress Series 336: 99-110.

Clarke, K.R. 1993. Non-parametric multivariate analyses of changes in community structure. Australian Journal of Ecology 18: 117-143.

Cottet, M., X. de Montaudouin, H. Blanchet, and P. Lebleu. 2007. Spartina anglica eradication experiment and in situ monitoring assess structuring strength of habitat complexity on marine macrofauna at high tidal level. Estuarine, Coastal and Shelf Science 71: 629-640.

Craft, C., and J. Sacco. 2003. Long-term succession of benthic infauna communities on constructed Spartina alterniflora marshes. Marine Ecology Progress Series 257: 45-58.

Frid, C.L.J., and R. James. 1988. The role of epibenthic predators in structuring the marine invertebrate community of a British coastal salt marsh. Netherlands Journal of Sea Research 22: 307-314.

Gray, J.S., and M. Elliot. 2009. Ecology of marine sediments; from science to management, 2nd ed, 226. Oxford: Oxford University Press.

Gribsholt, B., and E. Kristensen. 2003. Benthic metabolism and sulfur cycling along an inundation gradient in a tidal Spartina anglica marsh. Limnology \& Oceanography 48: 2151-2162.

Hampel, H., M. Eliott, and A. Catrijsse. 2009. Macrofaunal communities in the habitats of intertidal marshes along the salinity gradient of the Schelde estuary. Estuarine, Coastal and Shelf Science 84: 45-53.

Hedge, P., and L.K. Kriwoken. 2000. Evidence for effects of Spartina anglica invasion on benthic macrofauna in Little Swanport estuary, Tasmania. Austral Ecology 25: 150-159.

Jackson, D., C.F. Mason, and S.P. Long. 1985. Macro-invertebrate populations and production on a salt-marsh in east England dominated by Spartina anglica. Oecologia 65: 406-411.

Janousek, C.N. 2009. Taxonomic composition and diversity of microphytobenthos in southern California marine wetlands habitats. Wetlands 29: 163-175.

Jones, C.G., J.H. Lawton, and M. Shachak. 1994. Organisms as ecosystem engineers. Oikos 69: 373-386.

Lana, P.C., and C. Guiss. 1991. Influence of Spartina alterniflora on structure and temporal variability of macrobenthic associations in a tidal flat of Paranagua Bay (southeastern Brazil). Marine Ecology Progress Series 73: 231-244.

Lana, P.C., and C. Guiss. 1992. Macrofauna-plant biomass interactions in a euhaline salt marsh in Paranagua Bay (SE Brazil). Marine Ecology Progress Series 80: 57-64.

Levin, L.A., and T.S. Talley. 2000. Influences of vegetation and abiotic environmental factors on salt marsh invertebrates. In Concepts and controversies in tidal marsh ecology, ed. M.P. Weinstein and D.A. Kreeger, 661-707. Dordrecht: Springer. doi:10.1007/0-30647534-0 30.

Levin, L.A., C. Neira, and E.D. Grosholz. 2006. Invasive cordgrass modifies wetland trophic function. Ecology 87: 419-432.

Möller, I., T. Spencer, J.R. French, D.J. Leggett, and M. Dixon. 1999. Wave transformation over salt marshes: A field and numerical 
modelling study from North Norfolk, England. Estuarine, Coastal and Shelf Science 49: 411-426.

Neira, C., L.A. Levin, and E.D. Grosholz. 2005. Benthic macrofaunal communities of three sites in San Francisco Bay invaded by hybrid Spartina, with comparison to uninvaded habitats. Marine Ecology Progress Series 292: 111-126.

Neira, C., E.D. Grosholz, L.A. Levin, and R. Blake. 2006. Mechanisms generating modification of benthos following tidal flat invasion by a Spartina hybrid. Ecological Applications 16: 1391-1404.

Neira, C., L.A. Levin, E.D. Grosholz, and G. Mendoza. 2007. Influence of invasive Spartina growth stages on associated macrofaunal communities. Biological Invasions 9: 975-993.

Neumeier, U., and C.L. Amos. 2006. The influence of vegetation on turbulence and flow velocities in European salt-marshes. Sedimentology 53: 259-277.

Paramor, O.A.L., and R.G. Hughes. 2004. The effects of bioturbation and herbivory by the polychaete Nereis diversicolor on loss of saltmarsh in south-east England. Journal of Applied Ecology 41: 449-463.

Ponnamperuma, F.N. 1972. The chemistry of submerged soils. Advances in Agronomy 24: 29-96.

Rader, D.N. 1984. Salt-marsh benthic invertebrates: Small-scale patterns of distribution and abundance. Estuaries 4A: 413-420.

Reise, K., E. Herre, and M. Sturm. 1994. Biomass and abundance of macrofauna in intertidal sediments of Königshafen in the northern Wadden Sea. Helgoländer Meeresuntersuchungen 48: 201-215.

Seys, J., M. Vincx, and P. Meire. 1999. Spatial distribution of oligochaetes (Clitellata) in the tidal freshwater and brackish part of the Schelde estuary (Belgium). Hydrobiologia 406: 119-132.

Talley, T.S., and L.A. Levin. 1999. Macrofaunal succession and community structure in Salicornia marshes of southern California. Estuarine, Coastal and Shelf Science 49: 713-731.

Temmerman, S., T.J. Bouma, J. van de Koppel, D. van der Wal, M.B. de Vries, and P.M.J. Herman. 2007. Vegetation causes channel erosion in a tidal landscape. Geology 35: 631-634.

Van Colen, C., A. De Backer, G. Meulepas, D. van der Wal, M. Vincx, S. Degraer, and T. Ysebaert. 2010. Diversity, trait displacements and shifts in assemblage structure of tidal flat deposit feeders along a gradient of hydrodynamic stress. Marine Ecology Progress Series 406: 79-89.

Van Damme, S., E. Struyf, T. Maris, T. Ysebaert, F. Dehairs, M. Tackx, C. Heip, and P. Meire. 2005. Spatial and temporal patterns of water quality along the estuarine salinity gradient of the Scheldt estuary (Belgium and The Netherlands): Results of an integrated monitoring approach. Hydrobiologia 540: 29-45.

Van de Koppel, J., D. van der Wal, J.P. Bakker, and P.M.J. Herman. 2005. Self-organization and vegetation collapse in salt-marsh ecosystems. The American Naturalist 165: E1-E12.

Van der Wal, D., A. Wielemaker-van den Dool, and P.M.J. Herman. 2008a. Spatial patterns, rates and mechanisms of saltmarsh cycles (Westerschelde, The Netherlands). Estuarine, Coastal and Shelf Science 76: 357-368.

Van der Wal, D., P.M.J. Herman, R.M. Forster, T. Ysebaert, F. Rossi, E. Knaeps, Y.M.G. Plancke, and S.J. Ides. 2008b. Distribution and dynamics of intertidal macrobenthos predicted from remote sensing: Response to microphytobenthos and environment. Marine Ecology Progress Series 367: 57-72.

Van der Wal, D., R.M. Forster, F. Rossi, H. Hummel, T. Ysebaert, F. Roose, and P.M.J. Herman. 2011. Ecological evaluation of an experimental beneficial use scheme for dredged sediment disposal in shallow tidal waters. Marine Pollution Bulletin 62: 99-108.

Van Wesenbeeck, B.K., J. Van de Koppel, P.M.J. Herman, J.P. Bakker, and T.J. Bouma. 2007. Biomechanical warfare in ecology; negative interactions between species by habitat modification. Oikos 116: $742-750$.

Wang, R., L. Yuan, and L. Zhang. 2010. Impacts of Spartina alterniflora invasion on the benthic communities of salt marshes in the Yangtze Estuary, China. Ecological Engineering 36: 799-806.

Whitcraft, C.R., and L.A. Levin. 2007. Regulation of benthic algal and animal communities by salt marsh plants: Impact of shading. Ecology 88: 904-917.

Ysebaert, T., M. Fettweis, P. Meire, and M. Sas. 2005. Benthic variability in intertidal soft-sediments in the mesohaline part of the Schelde estuary. Hydrobiologia 540: 197-216. 